\title{
Influence of the trade-wind inversion on the climate of a leeward mountain slope in Hawaii
}

\author{
Thomas W. Giambelluca ${ }^{1,2}$, Dennis Nullet ${ }^{1, *}$ \\ ${ }^{1}$ Department of Geography, University of Hawaii at Manoa, Honolulu, Hawaii 96822, USA \\ ${ }^{2}$ Water Resources Research Center, University of Hawaii at Manoa, Honolulu, Hawaii 96822, USA
}

\begin{abstract}
The climate of oceanic islands in the trade-wind belts is strongly influenced by the persistent subsidence inversion characteristic of the regions. In the middle and upper elevations of high volcanic peaks in Hawaii, climate is directly affected by the presence and movement of the inversion. The natural vegetation and wildlife of these areas are vulnerable to long-term shifts in the inversion height that may accompany global climate change. Better understanding of the climatic effects of the inversion will allow prediction of global-warming-induced changes in tropical mountain climate. To evaluate the influence of the inversion on the present climate of the mountain, solar radiation, net radiation, air temperature, humidity, and wind measurements were taken along a transect on the leeward slope of Haleakala, Maui. Much of the diurnal and annual variability at a given location is related to proximity to the inversion level, where moist surface air grades rapidly into dry upper air. The diurnal cycle of upslope and downslope winds on the mountain is evident in all measurements Measurements indicate that the climate of Haleakala can be described with reference to 4 zones: a marine zone, below about $1200 \mathrm{~m}$, of moist well-mixed air in contact with the oceanic moisture source; a fog zone found approximately between 1200 and $1800 \mathrm{~m}$, where the cloud layer is frequently in contact with the surface; a transitional zone, from about 1800 to $2400 \mathrm{~m}$, with a highly variable climate; and an arid zone, above $2400 \mathrm{~m}$, usually above the inversion where air is extremely dry due to its isolation from the oceanic moisture source.
\end{abstract}

\section{INTRODUCTION}

Weather in the Hawaiian islands is affected up to $70 \%$ of the time by a subsidence inversion found at 1200 to $2400 \mathrm{~m}$ above sea level (Blumenstock \& Price 1967). The stabilizing effect of the inversion modifies circulation by strongly inhibiting vertical motion. As a result, spatial patterns of cloudiness, rainfall, solar radiation, temperature, and humidity bear the imprint of the inversion's pervasive influence. The climate of the middle and upper elevations of Hawaii's highest mountains is directly affected by the presence and movement of the inversion. These regions are influenced from below by the well-mixed layer of moist air in equilibrium with the ocean surface and from above by clean, dry air in the descending limb of the Hadley cell circulation. The inversion, with moist air and often a cloud layer immediately below and dry air above,

\footnotetext{
- Present affiliation, Department of Geography and Planning, East Carolina University, Greenville, North Carolina 27858, USA.
}

moves along the mountain slope, making the climatic regime of the contact zone extremely variable. This movement is affected by the interplay between synoptic-scale (North Pacific anticyclone) and mesoscale (thermal upslope/downslope winds) circulation systems. Patterns of natural vegetation along the slope dramatically reflect the influence of the steep elevational climatic gradient.

Paleoecological evidence indicates that the height of the inversion varies with changes in global temperature (Selling 1948). If predictions of global warming due to an enhanced greenhouse effect are realized, the average inversion level is likely to move higher than its present elevation. While such a shift would have significant influences on sea-level climate throughout the tradewind belts, the climate of high mountains in the tropics, such as Haleakala, would experience dramatic changes. This is of particular importance ecologically because of the unique and often rare plant and animal communities found on high tropical mountains. According to L. Loope (Research Scientist, Haleakala National Park, pers. comm.), any climate changes associated with shifts in 


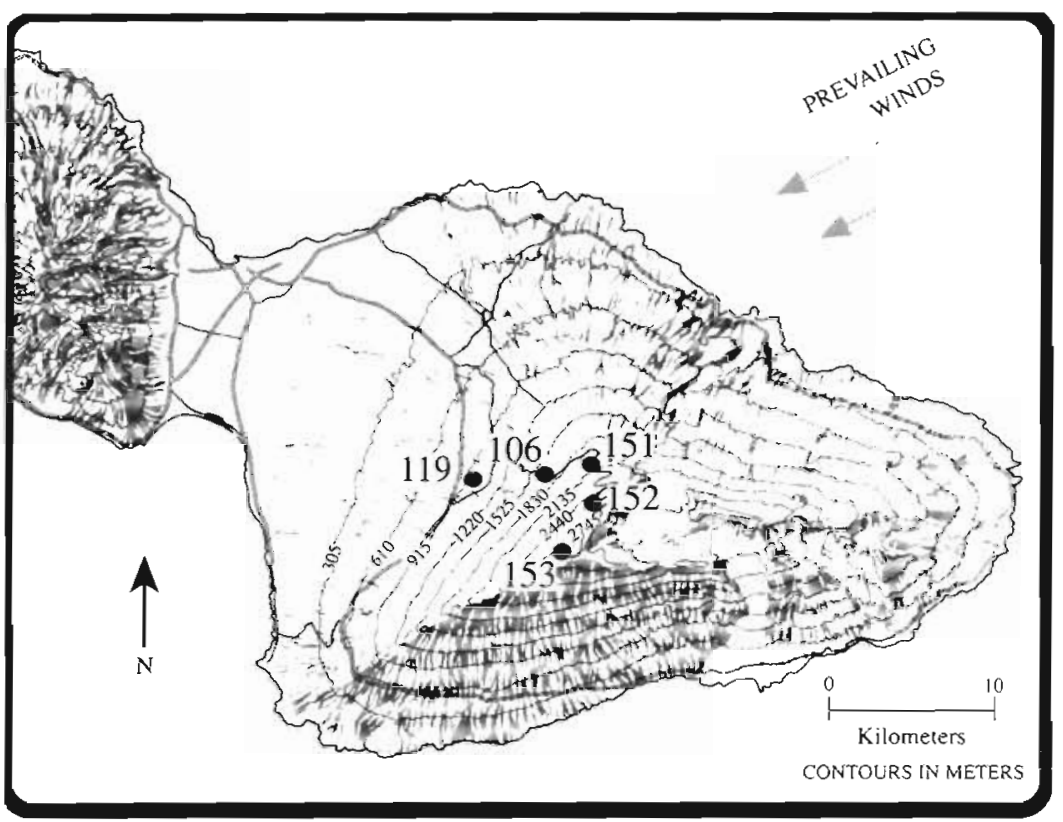

Fig. 1 Stalion locations, Haleakala, Maui, Hawaii

inversion height on Haleakala are likely to favor invasion into higher elevations of alien species with accompanying negative impacts on native species.

Regular atmospheric soundings by the U.S. National Weather Service at Lihue on the island of Kauai and at Hilo on Hawaii provide information on the free-atmosphere behavior of the inversion near the Hawaiian islands. The characteristics of the inversion near mountain slopes, however, differ from those in the free atmosphere due to mechanical and thermal influences of the mountain. With the exception of a limited number of observations on the slope of Mauna Loa by Mendonca (1969), Mendonca \& Iwaoka (1969), and
Garrett (1980), the vertical movement and effects of the inversion along mountain slopes which penetrate above it have not been systematically observed

The purpose of our on-going study is to monitor the climate along the slopes of Haleakala to facilitate prediction of changes in tropical mountain climate that may accompany a warming-induced rise in the inversion. The climate of the mountain slopes differs according to aspect. Windward slopes - those with aspects in the northeast quadrant - are subject to persistent orographic precipitation in contrast to drier leeward slopes. This paper addresses our first set of microclimatic measurements taken along an elevation transect on the west-

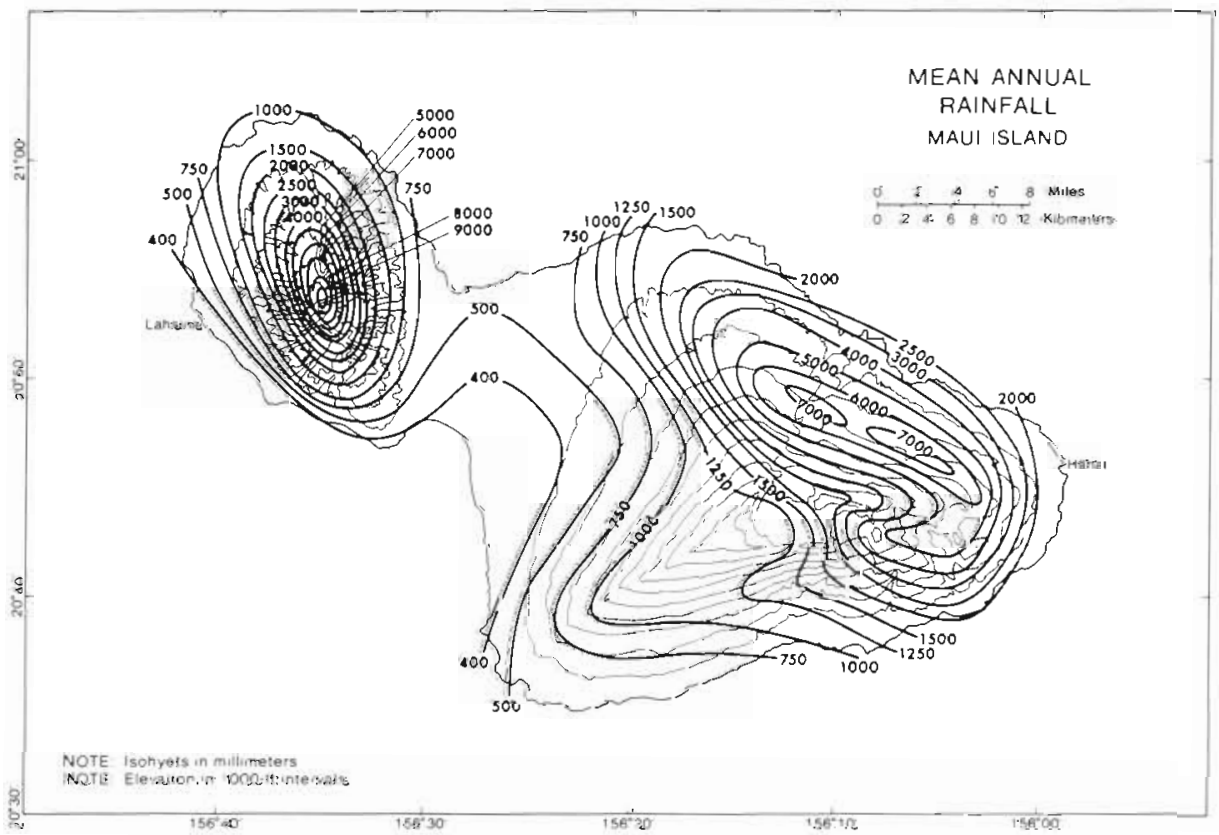

Fig. 2. Spatial distribution of mean annual rainfall $(\mathrm{mm})$ on Maui (Giambelluca et al. 1986) 
northwest-facing slope (Fig. 1). The focus here is on the climatic zonation on the leeward side of the mountain in relation to recognized atmospheric layers in the tradewind belt of the North Pacific. The network of microclimate stations is currently being extended to form a windward transect. Subsequent papers will provide the results of those measurements and deal with the issues of possible effects of global warming.

\section{PHYSICAL SETTING}

The climate of the open-ocean near the Hawaiian Islands is dry, with rainfall of about 0.6 to $0.7 \mathrm{~m} \mathrm{yr}^{-1}$ (Dorman \& Bourke 1979, Elliott \& Reed 1984), and days are generally sunny. Vertical motion is strongly inhibited when the inversion is present, and deep convection is relatively rare. Trade winds dominate the surface air flow and consequently also dominate island weather patterns. This is graphically demonstrated by the mean annual rainfall pattern for the Island of Maui shown in Fig. 2. Orographic lifting along windward slopes produces persistent cloudiness and rainfall of 9 to $11 \mathrm{~m} \mathrm{yr}^{-1}$ near the summits of 900 to $2000 \mathrm{~m}$ high mountains in Hawail, such as Puu Kukui on Maui (Giambelluca et al. 1986). For Haleakala on Maui, and Mauna Kea and Mauna Loa on the island of Hawaii, mountains that penetrate the inversion level, the inversion suppresses upslope flow, forcing the circulation to split and flow around rather than over the higher elevations (Leopold 1949). As is evident for Haleakala in Fig. 2 . maximum rainfall on these higher mountains is generally less intense and is not found at the summit, but occurs on the windward slopes at elevations lower than the rainfall maxima of the lower mountains (Giambelluca et al. 1986).

In describing the atmosphere in the vicinity of Hawaii, Riehl et al. (1951) identified 4 layers: subcloud, cloud, inversion, and free atmosphere. Over the open ocean, the subcloud layer extends from the surface to the lifting condensation level at about 600 to $800 \mathrm{~m}$. Cumulus clouds form between that level and the inversion base at around $2000 \mathrm{~m}$. The thickness of the inversion layer itself averages about $400 \mathrm{~m}$, above which is the dry stable air of the free atmosphere. Each of the boundaries varies in height in response to large-scalecirculation features and surface heating. This layered structure disappears when trade winds are displaced by cyclonic system. Over islands, the base of the cloud layer increases with distance from the windward shore. This is an effect of net drying of the subcloud layer brought about by moisture loss from rainout, downmixing of dry air from aloft, and heating from the land surface (Lavoie 1974).

The height and strength of the inversion are influ- enced by both synoptic-scale and mesoscale circulation systems. In general, the free-atmosphere inversion is regulated by the proximity and strength of the North Pacific anticyclone. Cyclonic circulation associated with frontal passage, upper atmospheric troughs, surface lows, and mid-tropospheric disturbances (Kona storms), interrupts subsidence and eliminates the inversion. Near mountains which penetrate the inversion, further complexity is added by mechanical disturbance and local thermal circulations. Daytime heating of the slopes produces upslope winds pushing moist marine air to higher elevations and lifting the inversion.

Mendonca \& Iwaoka (1969) found that temperature and humidity transects taken at the surface along the slope of Mauna Loa closely match those of free-atmosphere soundings in the early morning, but are affected by heating and upslope motion in the afternoon. They noted that daytime upslope winds carry smoke, dust, and other contaminants which tend to concentrate near the inversion. On Haleakala, clouds resulting from upslope winds typically begin forming in late morning and by early afternoon have lifted or penetrated the base of the inversion along the mountain slopes and brought light rainfall to the middle elevations. Penetration of this shallow, moist air layer affects the diurnal pattern of all of the climate elements discussed in this paper.

The trade-wind inversion is associated with distinct changes in vegetation along Hawaii's high mountain slopes. Original vegetation of the western slopes of Haleakala volcano is relatively intact above about $1800 \mathrm{~m}$ elevation and consists of shrubland dominated by Styphelia tameiameiae, Vaccinium reticulatum, Sophora chrysophylla, and Coprosma montana. Below $1800 \mathrm{~m}$ elevation, the original forest vegetation was destroyed in the 19th century by fire and cattle browsing. The forest at 1200 to $1800 \mathrm{~m}$ probably resembled the 'Middle-Elevation Cloud-Belt Forest Zone', dominated by Acacia koa and Metrosideros polymorpha, described by Medeiros et al. (1986). The 1200 to $1800 \mathrm{~m}$ zone at present is open pastureland with scattered groves of introduced Eucalyptus spp. Remnants of a formerly species-rich dryland forest survived until the 19 th century at 600 to $1200 \mathrm{~m}$ in spite of intensive Polynesian agriculture (Medieros et al. 1986, L. Loope pers. comm.). The 600 to $1200 \mathrm{~m}$ area is at present dominated by residential and agricultural land uses.

Rain forest, dominated by Metrosideros polymorpha, occurs on windward slopes of Haleakala. Leuschner \& Schulte (1991) found that the abrupt upper limit of rainforest on Maui (ca $1950 \mathrm{~m}$ elevation) results principally from an abrupt change in water availability near the inversion rather than from a temperature difference. The association between vegetation patterns and 
Table 1. Microclimate stations

\begin{tabular}{|c|c|c|c|c|}
\hline No. & Name & $\begin{array}{l}\text { Elevation } \\
(\mathrm{m})\end{array}$ & Operating period & Land cover \\
\hline 119 & Kula Ag & 950 & 15 Jun $1988-30$ Jun 1990 & Grass, bare soil \\
\hline 106 & Puu Pahu & 1650 & 15 Jun $1988-30$ Jun 1990 & Pasture \\
\hline 151 & Park $\mathrm{HQ}$ & 2130 & 16 Jun $1988-30$ Jun 1990 & Shrub, basaltic outcrop \\
\hline 152 & Nene Nest & 2600 & 12 Mar 1990-30 Jun 1990 & Volcanic cinder, sparse grass and fern \\
\hline 153 & Summit & 3000 & 30 Mar 1990-30 Jun 1990 & Volcanic cinder \\
\hline
\end{tabular}

inversion height allowed Selling (1948) to conclude, based on pollen data taken from mires on Maui, that drastic shifts in inversion height have accompanied past global climate variations. Evidence of dry land vegetation at a site now among the wettest in the world led Selling to conclude that during postglacial times the inversion may have been about $500 \mathrm{~m}$ lower than present during relatively cool periods and higher than present during relatively warm periods.

\section{MEASUREMENTS}

Haleakala, a dormant volcano, rises from sea level to $3055 \mathrm{~m}$ over a horizontal distance of only about $20 \mathrm{~km}$. An excellent paved road allows easy access to the summit through Haleakala National Park on the leeward slope. The mountain provides a natural laboratory for the study of elevation effects on tropical climate. To characterize the climate near the inversion, a transect of 5 stations was maintained along the road on Haleakala's western slope between 950 and $3000 \mathrm{~m}$ for periods of up to 2 yr (Fig. 1). A summary of the sites, and the periods of record for each station, is given in Table 1. Global radiation ( $\mathrm{W} \mathrm{m}^{-2}$ ) was measured with Eppley Model 8-48 ('black and white') pyranometers, net radiation ( $\mathrm{W} \mathrm{m}^{-2}$ ) with Fritschen-type net radiometers (Qualimetrics Model 3032 and Radiation Energy Balance Systems Model $Q \cdot 5)$, air temperature $\left({ }^{\circ} \mathrm{C}\right)$ and humidity $(\%)$ with Vaisala Model HMD-30-YB sensors, and wind ( $\mathrm{m} \mathrm{s}^{-1}$ ) with both click-type (Qualimetrics Model W203-HF) and voltage-generating (Qualimetrics Model 2011) 3-cup anemometers. Data were recorded at hourly invervals on Licor Model LI-1000 dataloggers.

\section{ANALYSIS}

Hourly data were checked for errors by visual examination of the time series. Values out of the expected range or inconsistent with other measurements were removed. Reliability varied by sensor and location (Table 2). Mean hourly values of each element for each month were computed to obtain mean monthly diurnal patterns. Mean daily values for each month were then obtained by averaging the 24 mean hourly values. Any month with fewer than 10 data values for any hour was not included. Mean daily values for each month of all measured quantities and of the derived quantity, vapor pressure, are listed in Table 3. The months of December and May are used as examples from Table 3 for illustrating elevation effects (Fig. 3). To determine the reduction in global radiation from the expected under cloudless skies, measured global radiation values are compared to clear-sky estimates based on the SPCTRAL2 model (Bird \& Riordan 1986). Mean hourly values for the month of May are depicted in Fig. 4 to illustrate diurnal effects. May was selected because records are relatively complete for all 5 stations. Fig. 5 illustrates the annual cycles of each element at each station.

\section{Elevation effects}

Fig. 3 depicts mean profiles of December and May global radiation, net radiation, temperature, relative humidity, vapor pressure, and wind. In Fig. 3a, b, estimated clear-day global radiation is shown for comparison with measured global and net radiation. In December (Fig. 3a), both global and net radiation are unchanged with elevation between 950 and $1650 \mathrm{~m}$. Both increase significantly between 1650 and $2130 \mathrm{~m}$. Attenuation of global radiation by clouds in December ranges from $36 \%$ at 950 and $1650 \mathrm{~m}$ to $27 \%$ at $2130 \mathrm{~m}$. Net radiation as a percentage of global radiation is 51 , 53 , and $56 \%$ for 950,1650 , and $2130 \mathrm{~m}$, respectively. In May (Fig. 3b), global radiation exhibits a distinct minimum at $1650 \mathrm{~m}$ and increases sharply above that elevation. Attenuation of global radiation by clouds is $49 \%$ at $1650 \mathrm{~m}$, dropping to $6 \%$ at the $3000 \mathrm{~m}$ elevation. In May, net radiation as a percentage of global radiation is $60 \%$ at 950,1650 , and $2130 \mathrm{~m}, 52 \%$ at $2600 \mathrm{~m}$, and $56 \%$ at $3000 \mathrm{~m}$.

While no inverse temperature lapse rate is seen in the mean profiles (Fig. 3c), the inversion's influence is apparent in the reduced temperature gradient above $1650 \mathrm{~m}$. Below this level, the lapse rate averages about $0.006{ }^{\circ} \mathrm{C} \mathrm{m}^{-1}$ in December and May. Between 1650 and 
Table 2. Periods of operation of Haleakala climate stations $\left(n_{i} m o\right)$ and portion of operating time during which reliable data were obtained $(\%)$. $R_{\mathrm{g}}$ : global radiation; $\mathrm{R}_{\mathrm{n}}$ : net radiation; $\mathrm{T}_{\mathrm{d}}$ : air temperature; $\mathrm{RH}$ : relative humidity; UU: wind speed

\begin{tabular}{|c|c|c|c|c|c|c|c|c|c|c|}
\hline \multirow[t]{2}{*}{ Sensor } & \multicolumn{2}{|c|}{ Stn 119} & \multicolumn{2}{|c|}{ Stn 106} & \multicolumn{2}{|c|}{ Stn 151} & \multicolumn{2}{|c|}{ Stn 152} & \multicolumn{2}{|c|}{ Stn 153} \\
\hline & $\mathrm{n}$ & $\%$ & $\mathrm{n}$ & $\%$ & $\mathrm{n}$ & $\%$ & $\mathrm{n}$ & $\%$ & $\mathrm{n}$ & $\%$ \\
\hline $\mathrm{R}_{\mathrm{g}}$ & 26 & 94.4 & 26 & 91.6 & 26 & 73.6 & 5 & 99.8 & 4 & 100.0 \\
\hline$R_{n}$ & 26 & 94.5 & 26 & 98.2 & 26 & 93.4 & 5 & 99.8 & 4 & 100.0 \\
\hline$T_{d}$ & 19 & 63.2 & 19 & 76.7 & 19 & 77.0 & 5 & 99.0 & 4 & 76.0 \\
\hline $\mathrm{RH}$ & 19 & 63.2 & 19 & 55.2 & 19 & 80.6 & 5 & 85.4 & 4 & 99.8 \\
\hline UU & 19 & 78.4 & 19 & 85.2 & 19 & 83.8 & 5 & 99.8 & 4 & 99.8 \\
\hline
\end{tabular}
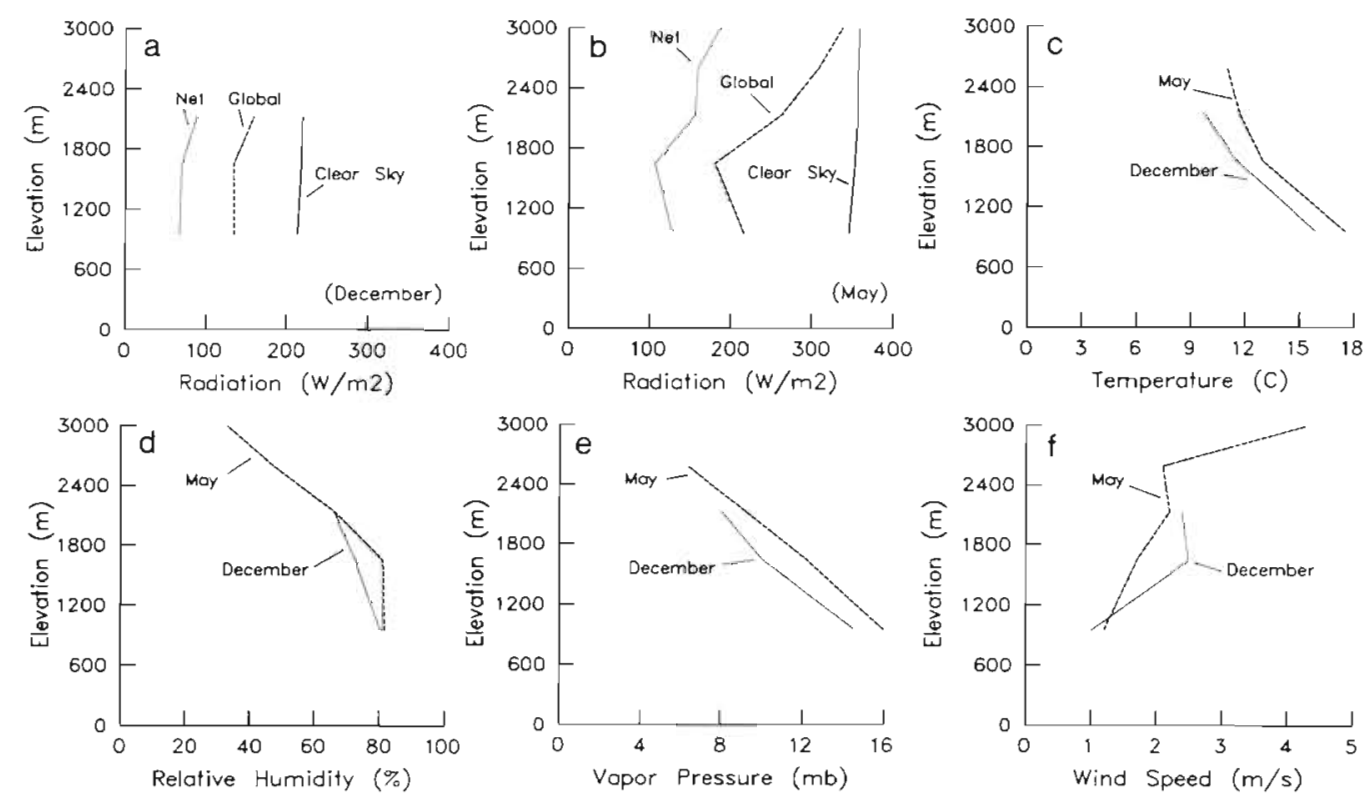

Fig. 3. Mean profiles of (a) clear sky, global, and net radiation ( $\mathrm{W} \mathrm{m}^{-2}$ ) for December, (b) clear sky, global, and net radiation (W $\mathrm{m}^{-1}$ for May, (c) temperature $\left({ }^{\circ} \mathrm{C}\right)$ for December and May, (d) relative humidity (\%) for December and May, (e) vapor pressure (mb) for December and May, and (f) wind speed $\left(\mathrm{m} \mathrm{s}^{-1}\right)$ for December and May

$2130 \mathrm{~m}$, however, where the inversion frequently lies, the gradient is reduced to $0.004{ }^{\circ} \mathrm{C} \mathrm{m}^{-1}$ in December and $0.003{ }^{\circ} \mathrm{C} \mathrm{m}^{-1}$ in May. The May reduction is greater because of the inversions's greater persistence during the summer half-year.

In general, relative humidity decreases with elevation throughout the transect in winter and summer (Fig. 3d). The only exception is in May when the relative humidity at $1650 \mathrm{~m}$ is about the same as that of the $950 \mathrm{~m}$ level. Because relative humidity is influenced by both temperature and the water content of the air, vapor pressure profiles (Fig. 3e) differ somewhat from the relative humidity profiles. In both December and May, vapor pressure decreases linearly with elevation.

Wind speed is greatly influenced by local topography and instrument exposure. Despite these site-specific influences, it is apparent from Fig. $3 f$ that average wind speed generally increases with elevation both in winter and summer. The exceptions are at $2130 \mathrm{~m}$ in December and $2600 \mathrm{~m}$ in May, each of which is slightly less windy than the station below it.

\section{Diurnal effects}

Average diurnal patterns of each element are shown in Fig. 4 for May, which includes one of 2 days (25 May and 20 July) when the noon sun is at the zenith over the study site. The global radiation cycle is shown in Fig. 4a. At the upper site, global radiation is reduced only $6 \%$ from modeled clear sky values and thus represents nearly cloud-free conditions. The graph clearly indicates a diurnal pattern in the reduction of global radiation by clouds. The mornings begin with a sharp rise in global radiation receipt, indicating clear skies. As the day progresses, clouds move upslope and begin to block incoming solar radiation. The effect of clouds is seen later in the day at the higher elevations. The maximum reduction of solar radiation occurs at $1650 \mathrm{~m}$, just below the inversion. At $2600 \mathrm{~m}$, early afternoon clouds cause a depression in global radiation values, and then dissipate by about 16:00 h local time.

Fig. 4b shows that the net radiation pattern follows the global radiation pattern during the day. At night, 
Table 3. Mean dally global. radiation, net radition, temperature, relative humidity, vapor pressure, and wind speed by month

\begin{tabular}{|c|c|c|c|c|c|c|c|c|c|c|c|c|}
\hline $\begin{array}{l}\text { Elevation } \\
\qquad(\mathrm{m})\end{array}$ & $\operatorname{Jan}$ & Feb & Mar & Apr & May & Jun & Jul & Aug & Sep & Oct & Nov & Dec \\
\hline \multicolumn{13}{|c|}{ Global radiation $\left(\mathrm{W} \mathrm{m}^{-2}\right.$ ) } \\
\hline 950 & 141 & 151 & 182 & 188 & 217 & 211 & 215 & 196 & 187 & 161 & 149 & 136 \\
\hline 1650 & 132 & 146 & 171 & 163 & 182 & 191 & 183 & 175 & 162 & 145 & 147 & 134 \\
\hline 2130 & 203 & - & 266 & 218 & 263 & 303 & 289 & 256 & 216 & 174 & 163 & 160 \\
\hline 2600 & - & - & 320 & 272 & 308 & 322 & - & - & - & - & - & - \\
\hline 3000 & - & - & 331 & 316 & 339 & 338 & - & - & - & $=$ & - & - \\
\hline \multicolumn{13}{|c|}{ Net radiation $\left(\mathrm{W} \mathrm{m}^{-2}\right)$} \\
\hline 950 & 76 & 89 & 110 & 118 & 130 & 124 & 133 & 118 & 112 & 97 & 82 & 69 \\
\hline 1650 & 68 & 78 & 94 & 96 & 109 & 112 & 113 & 100 & 95 & 86 & 81 & 72 \\
\hline 2130 & 98 & 107 & 144 & 133 & 158 & 164 & 169 & 155 & 136 & 119 & 102 & 90 \\
\hline 2600 & - & - & 138 & 136 & 161 & 179 & - & - & - & - & - & - \\
\hline 3000 & - & - & 202 & 176 & 189 & 201 & - & - & - & - & - & - \\
\hline \multicolumn{13}{|c|}{ Temperature $\left({ }^{\circ} \mathrm{C}\right)$} \\
\hline 950 & 16.4 & 15.0 & 15.7 & 17.1 & 17.5 & 1.8 .4 & 18.2 & 18.4 & 18.8 & - & 17.6 & 15.9 \\
\hline 1650 & 13.0 & 10.9 & 11.4 & 12.8 & 13.0 & 14.9 & 15.7 & 1.5 .2 & 15.6 & 15.2 & 14.3 & 11.6 \\
\hline 2130 & 8.9 & 8.7 & 11.1 & 12.5 & 11.7 & 14.3 & 12.5 & 12.2 & 12.5 & 12.5 & 12.5 & 9.8 \\
\hline 2600 & - & - & 11.3 & 11.1 & 11.0 & 13.3 & - & - & - & - & - & - \\
\hline 3000 & - & - & - & 10.2 & 12.2 & 10.5 & - & - & - & $\sim$ & - & - \\
\hline \multicolumn{13}{|c|}{ Relative humidity (\%) } \\
\hline 950 & 86.0 & 84.0 & 83.2 & 85.6 & 81.6 & 81.6 & 76.6 & 79.9 & 80.4 & - & 80.4 & 80.8 \\
\hline 1650 & 74.2 & 79.8 & 78.3 & 81.5 & 81.2 & 81.3 & - & - & 82.9 & 83.7 & 74.3 & 72.9 \\
\hline 2130 & 54.3 & 71.5 & 52.3 & 59.0 & 66.6 & 57.9 & 62.8 & 69.3 & 67.4 & 72.4 & 57.4 & 66.2 \\
\hline 2600 & - & - & 23.1 & 46.8 & 47.7 & 36.7 & - & - & - & - & - & - \\
\hline 3000 & - & - & - & 31.9 & 33.0 & 33.9 & - & - & - & - & - & - \\
\hline \multicolumn{13}{|c|}{ Vapor pressure (mb) } \\
\hline 950 & 1.6 .0 & 14.3 & 14.8 & 16.7 & 16.3 & 17.3 & 16.0 & 16.9 & 17.4 & - & 16.2 & 14.6 \\
\hline 1650 & 1.1 .1 & 10.4 & 10.5 & 12.0 & 12.2 & 13.8 & - & - & 14.7 & 14.4 & 12.1 & 10.0 \\
\hline 2130 & 6.2 & 8.0 & 6.9 & 8.5 & 9.2 & 9.4 & 9.1 & 9.8 & 9.8 & 10.5 & 8.3 & 8.0 \\
\hline 2600 & - & - & 3.1 & 6.2 & 6.3 & 5.6 & - & - & - & - & - & - \\
\hline 3000 & - & - & - & 4.0 & 4.7 & 4.3 & - & - & - & - & - & - \\
\hline \multicolumn{13}{|c|}{ Wind speed $\left(\mathrm{m} \mathrm{s}^{-1}\right)$} \\
\hline 950 & 0.9 & 1.3 & 1.2 & 1.0 & 1.2 & 0.8 & 0.9 & 0.8 & 0.8 & 0.5 & 0.8 & 1.0 \\
\hline 1650 & 2.3 & 2.8 & 2.2 & 1.5 & 1.7 & 1.6 & 2.0 & 1.8 & 1.9 & 1.8 & 2.1 & 2.5 \\
\hline 2130 & 3.5 & 2.6 & 2.5 & 2.2 & 2.2 & 3.3 & 3.0 & 2.3 & 2.2 & 1.9 & 2.0 & 2.4 \\
\hline 2600 & - & - & 1.8 & 2.4 & 2.1 & 3.1 & - & - & - & - & - & - \\
\hline 3000 & - & - & - & 4.1 & 4.3 & 6.0 & - & - & - & - & - & - \\
\hline
\end{tabular}

longwave radiation loss to space increases with elevation. Between 21:00 and 05:00 $\mathrm{h}$, radiation loss averages $24,28,37,77$, and $81 \mathrm{~W} \mathrm{~m}^{-2}$ at 950,1650 , 2130,2600 , and $3000 \mathrm{~m}$, respectively. Because the 2 lowest sites are often within or beneath a cloud layer, longwave radiation loss increases as the night progresses as a result of an increasingly clear sky. At the 3 uppermost sites, usually above the clouds, longwave loss gradually decreases as the ground cools.

Fig $4 \mathrm{c}$ shows diumal temperature patterns. No temperature data are available for May at the summit due to instrument malfunction. As mentioned earlier, the temperature difference among the middle 3 stations is small because of the inversion. Each temperature curve is marked by abrupt changes at sunrise and sunset. Temperature at $1650 \mathrm{~m}$ remains remarkably constant throughout the daylight hours, while at 2600 $m$, there is gradual cooling after a noon peak. At 950 and $2130 \mathrm{~m}$, temperatures rise rapidly in the first $2 \mathrm{~h}$ of sunlight, then continue warming gradually, reaching the diurnal maximum at 15:00 h local time.

The relative humidity curves (Fig. 4 d) show a marked diurnal pattern. At the lowest station, average relative humidity is lower during the daylight hours than at night. This is typical of low elevation sites in Hawaii where higher temperature during the day more than compensates for an increase in vapor pressure, so that relative humidity (inversely related to temperature) decreases. The higher stations, however, all show an increase in relative humidity between mid-morning and late afternoon. This must be attributed to moist air flowing to high elevations with daytime upslope flow.

The diurnal cycle in vapor pressure at each station, shown in Fig. 4e, is marked by a daytime maximum. At 
Fig. 4. Mean May diurnal patterns of (a) global radiation $\left(\mathrm{W} \mathrm{m}^{-2}\right)$, (b) net radiation ( $\mathrm{W} \mathrm{\textrm {m } ^ { - 2 }}$ ), (c) temperature $\left({ }^{\circ} \mathrm{C}\right)$, (d) relative humidity $(\%)$, (e) vapor pressure (mb), and (f) wind speed $\left(\mathrm{m} \mathrm{s}^{-1}\right)$

all stations, vapor pressure begins to increase at sunrise, the expected result of increasing rates of evaporation and transpiration with increasing solar radiation. Later in the morning increases are enhanced at higher stations by upslope flow bringing moist surface air to progressively higher elevations. Daily vapor pressure maxima are reached at 13:00 or 14:00 h local time for the 3 lower stations, and at 15:00 $\mathrm{h}$ for the 2 upper stations. Similarly at night, dry air is brought to progressively lower elevations by downslope flow. Minima occur at 23:00 h for the 2 highest stations, 03:00 h for the middle stations, and 06:00 h for the lowest 2 stations. Diurnal vapor pressure ranges are about 6 to $7 \mathrm{mb}$ for all stations except the summit, where it is less than $5 \mathrm{mb}$.

The diurnal wind pattern is shown in Fig. 4f. In general, the diurnal pattern becomes less pronounced with elevation, and at the highest site, no diurnal pattern is evident. At the lowest site, low nighttime wind speeds give way to increasing wind speeds during the day. The intermediate elevation sites lie between these extremes. Also, at the 4 lowest sites marked depressions in wind speed are observed at about 08:00 and 19:00 h local time.

\section{Annual cycle}

The annual cycles of global and net radiation (Fig. $5 \mathrm{a}, \mathrm{b})$ are indicative of the march of solar declination and daylength as well as cloud cover variations related to season. Cloud cover probably has significant interannual variability, and thus our measurements represent a small sample. Nevertheless, the general patterns of insolation and radiation balance are apparent. The annual global radiation peak occurs either in May or June for all 5 stations (although annual cycles are incomplete for the upper 2 stations). The maximum net radiation at the 3 levels for which 12 mo of data are available occurs in July.

The small annual temperature cycle typical of marine tropical climates can be seen in Fig. $5 \mathrm{c}$. The coldest 

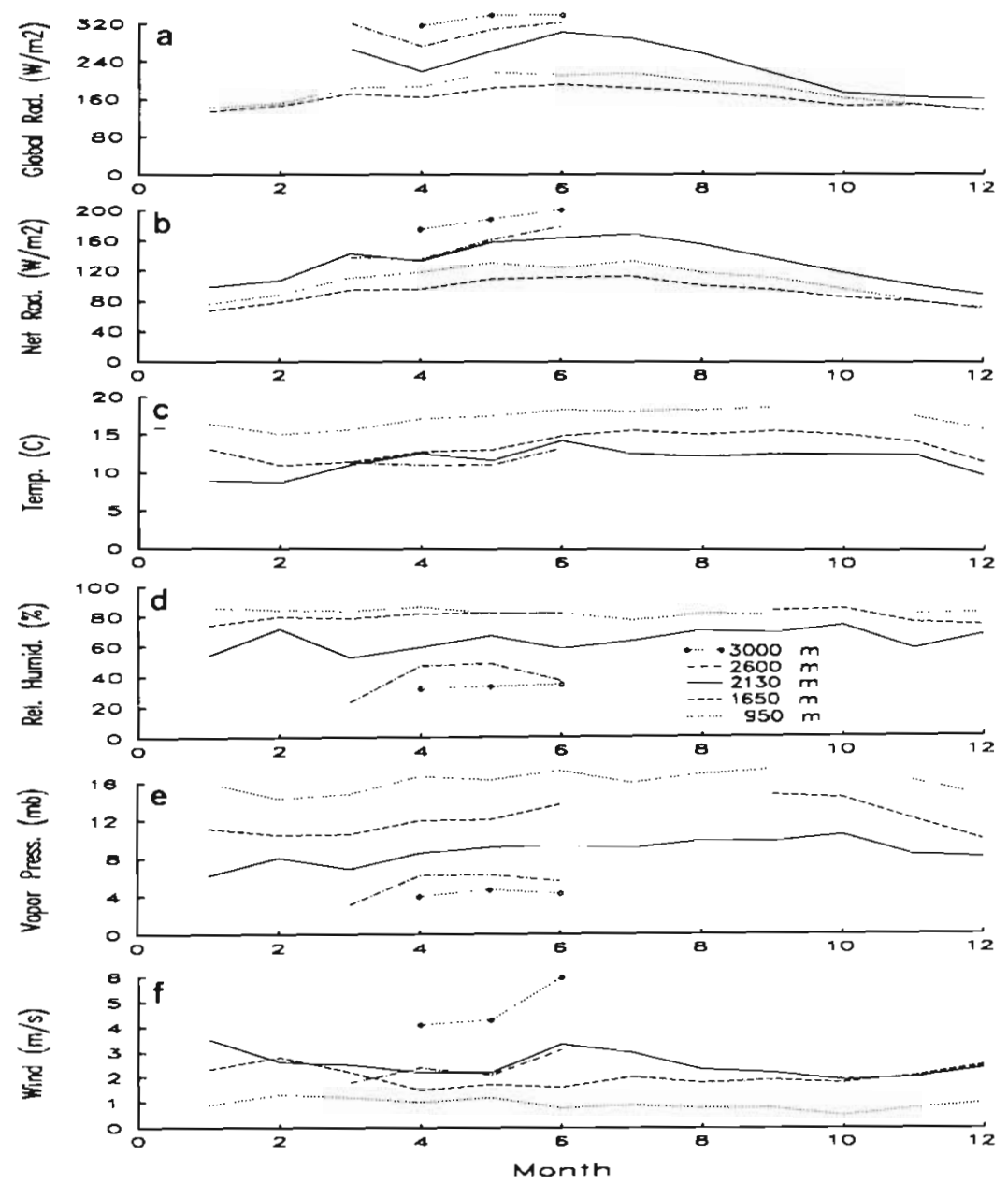

Fig. 5. Mean annual patterns of (a) global radiation ( $\left.\mathrm{W} \mathrm{m}^{-2}\right)$, (b) net radiation ( $W$ $\left.\mathrm{m}^{-2}\right), \quad(\mathrm{c})$ temperature $\left({ }^{\circ} \mathrm{C}\right)$, (d) relative humidity $(\%)$, (e) vapor pressure $(\mathrm{mb})$, and (f) wind speed $\left(\mathrm{m} \mathrm{s}^{-1}\right)$

month, February, is only 3 to $4^{\circ} \mathrm{C}$ cooler than the warmest months, July and August, at the 950, 1650, and $2130 \mathrm{~m}$ levels. It is interesting to note that the temperature difference between 1650 and $2130 \mathrm{~m}$ is very small during the period March through June. No annual cycle is apparent in the available relative humidity data (Fig. 5d). However, the vapor pressure curves (Fig. 5c) indicate September or October maxima and December, January, or February minima at the 3 lowest stations, in general accord with the annual cycle of evaporation. Although wind speed (Fig. 5f) is not strongly dependent on season, it is noteworthy that annual maxima occur in January or February for all 3 stations, and minima take place in October for 2 of the 3 lower stations

\section{DISCUSSION}

All of the climate variables presented in this report vary with elevation and are affected by the presence of the subsidence inversion. Clear skies prevail above the inversion and both global and net radiation are high.
The average lapse rate is small near the inversion as movement of the inversion layer up and down the slopes affects all levels above the lowest site. Humidity is much lower above the inversion and, on average, changes uniformly with elevation through the inversion layer. Average wind speed increases with elevation as the surrounding land area becomes smaller toward the summit of the mountain, reducing the frictional effect, and as higher velocity free-atmosphere winds are encountered.

While the inversion places a limit on the upward development of clouds in the free atmosphere, local heating allows moist air to penetrate to higher elevations in a thin layer close to the mountain. Lyons (1979) noted that the largest weather variations occur in response to the diurnal mountain heating cycle' on Haleakala. This diumal air movement pattern is evident in Fig. 4f, the average diumal wind speed. At the lower elevations, nighttime winds follow the normal trade wind flow which is enhanced by katabatic downslope winds from the cold slopes above. During the day, the winds reverse and anabatic upslope winds prevail. The decreases in wind speed in early 
morning and late afternoon reflect this change in wind direction.

During daylight hours, cloudiness resulting from upslope flow is seen at progressively higher elevations. Clouds affect the radiation balance at the lowest stations first, starting about 09:00 to 10:00 h local time, but do not significantly reduce insolation until after noon at the highest stations. At the upper 3 stations, the cloud layer is less frequent and thinner, creeping tentatively up the mountain as an increasingly shallow layer. The reduction in global radiation resulting from these ground-hugging clouds is much less than that experienced by the 2 lowest stations, above which deeper cloud development is possible.

As anabatic winds develop in the morning, relative humidity rises at all but the lowest site as moister air from below is brought to higher elevations. The upslope flow carrying thin clouds and moist air also moderates the diurnal temperature pattern, keeping temperatures fairly uniform throughout the daylight hours.

Our data are not sufficient to make strong statements regarding the influence of the inversion on the annual climate cycle of the mountain slope. However, there are indications that differences among seasons in the frequency and strength of the inversion are important in controlling variations in solar and net radiation and air temperature. This appears to be related to a stronger and more persistent inversion in summer than in winter.

\section{CONCLUSION}

Our observations allow us to characterize the climate along the leeward slope of Haleakala with reference to the 4 atmospheric layers identified by Riehl et al. (1951). Corresponding climate zones along the slope can be delineated according to elevation with respect to the heights of the cloud base and the inversion base. Because of the thermal and mechanical influences of the land mass, the heights of the boundaries between adjacent climate zones differ from the heights of corresponding free-atmosphere layers and vary from windward to leeward slopes. The 4 climate zones with the corresponding atmospheric layers in parentheses are (1) marine (subcloud) (2) fog (cloud), (3) transitional (inversion), and (4) arid (free atmosphere). While at any given instant distinct boundaries may be apparent between each of the 4 atmospheric layers, the climatic zones we describe reflect averaged conditions produced by fluctuations in the heights and strengths of the atmospheric layers.

The marine zone extends from sea level to the mean cloud base level at ca $1200 \mathrm{~m}$ elevation on the leeward Haleakala slope. This zone is almost always below the inversion base and includes most of the land area of the Hawaiian Islands. Stn 119 (Kula Ag) at $950 \mathrm{~m}$ is characteristic of this zone. Because of the long fetch over open ocean, temperature and humidity profiles in the lower zone are adjusted to the sea surface. Air in this layer is well mixed and temperature and vapor pressure decrease approximately linearly with height. Although the cloud base is usually above $1200 \mathrm{~m}$ on the western slopes of Haleakala, the upper portion of this zone occasionally experiences fog. Along the windward slope this zone is shallower, with an upper boundary at about $600 \mathrm{~m}$.

The fog zone extends from the mean cloud base level, at about $1200 \mathrm{~m}$, to the lower limit of the most frequent inversion base height range at about $1800 \mathrm{~m}$. The station at $1650 \mathrm{~m}$ is representative of the fog zone. Because of the frequent cloud presence, this zone experiences the lowest global and net radiation of the transect. During the day, rapid variations in cloud conditions and frequent down-mixing of dry air through the inversion layer produce high variability in humidity and radiation. Sites experience abrupt changes from low-light, near-moisture-saturation conditions to highintensity, low-humidity conditions. Along the windward slopes, the fog zone is thicker, probably extending from about 600 to $2000 \mathrm{~m}$.

The transitional zone covers the range of heights where the inversion base is most frequently found, from 1800 to $2400 \mathrm{~m}$. Within this elevation range, any of the 4 atmospheric layers can be present at a given time resulting in extreme variability, especially in humidity. Rapid fluctuation of the inversion height can produce relative humidity changes of $60 \%$ or more over a few minute period. When clouds are present beneath the inversion, short-term variability of global and net radiation are similarly high. Diurnal and synoptic cycles induce humidity and radiation variability at longer time scales.

The arid zone extends upward from the upper limit of the most frequent inversion base height at about 2400 $\mathrm{m}$. Air within this layer is isolated from the oceanic moisture source. It originates high in the troposphere and, having descended in its trajectory around the subtropical anticyclone, is very dry and relatively warm. The upper slopes of the mountain which penetrate above the inversion are exposed to an extremely arid atmosphere most of the time. The sky is frequently clear at these elevations producing very high insolation. Net radiation is high during daylight hours, but strongly negative at night because of rapid longwave loss into the thin, clear atmosphere. High clouds occasionally affect radiation. During occasions when the inversion is absent or unusually high, moist air and clouds can reach this zone.

The original vegetation zones on leeward Haleakala 
appear to reflect the climate zonation described herein. Previously existing dryland forest below $1200 \mathrm{~m}$ and cloud-belt forest between 1200 and $1800 \mathrm{~m}$, and the intact shrubland above $1800 \mathrm{~m}$, correspond well with the observations along our transect. The success of native and alien flora of the fog and transitional zones is apparently dependent on adaptation to abrupt changes in sunlight, humidity, and evaporative demand. Should significant global warming occur, the zonal climates and associated vegetation are likely to migrate upslope with increasing inversion height. Consequently the area in which endemic species have competitive advantage may shrink.

Acknowledgements. In conducting fieldwork on Maui, the authors were given support, encouragement, and assistance by numerous individuals. We extend our gratitude especially to Jotoku and Doris Asato, Ronald Nagata, Lloyd Loope, Ted Rodrigues, Kathy Wakelee, and Bill Minyard. This research has been supported with funding from the University of Hawaii Research Council, the Water Resources Institute Program of the U.S. Geological Survey, and the Cooperative National Parks Resources Study Unit.

\section{LITERATURE CITED}

Bird, R. E., Riordan, C. (1986). Simple solar spectral model for direct and diffuse irradiance on horizontal and tilted planes at the earth's surface for cloudless atmospheres. J. Climate appl. Meteorol. 25: 87-97

Blumenstock, D. I., Price, S. (1967). Climate of Hawaii. Climates of the States. Climatography of the States, No. 60-51, U.S. Department of Commerce

Dorman, C. E., Bourke, R. H. (1979). Precipitation over the

Editor: $V$ Meentemeyer
Pacific Ocean, $30^{\circ} \mathrm{S}$ to $60^{\circ} \mathrm{N}$. Mon. Weather Rev. 107 (7): 896-910

Elliott, W. P., Reed, R. K. (1984). A climatological estimate of precipitation for the world ocean. J. Climate appl. Meteorol. 23: 434-439

Garrett, A. J. (1980). Orographic cloud cover over the eastern slopes of Mauna Loa Volcano, Hawaii, related to insolation and wind. Mon. Weather Rev. 108: 931-941

Giambelluca, T. W. Nullet, M. A., Schroeder, T A. (1986). Rainfall atlas of Hawai'i. Report R76. Hawaii Department of Land and Natural Resources, Division of Water and Land Development, Honolulu

Lavoie, R. L. (1974). A numerical model of trade wind weather on Oahu. Mon. Weather Rev. 102:630-637

Leopold, L. B. (1949). The interaction of tradewind and sea breeze. Hawaii J. Meteorol. 6: 312-320

Leuschner, C., Schulte, M. (1991). Microclimatological investigations in the tropical alpine scrub of Maui, Hawaii: evidence of a drought-induced alpine timberline. Pacif. Sci. 45: $152-168$

Lyons, S. W. (1979). Summer weather on Haleakala, Maui. Department of Meteorology Technical Report UHMET 79-09, University of Hawaii. Honolulu

Medeiros, A. C., Loope, L. L., Holt, R. A. (1986). Status of native flowering plant species on the south slope of Haleakala, East Maui. Technical Report 59, Cooperative National Park Resources Study Unit, Department of Botany, University of Hawaii at Manoa, Honolulu

Mendonca, B. G. (1969). Local wind circulation on the slopes of Mauna Loa. J. appl. Meteorol. 8: 533-541

Mendonca, B. G., Iwaoka, W T (1969). The trade wind inversion at the slopes of Mauna Loa, Hawaii. J. appl. Meteorol. 8: $213-219$

Riehl, H., Yeh, T C., Malkus, J. J., La Seur, N. E. (1951). The northeast trade of the Pacific Ocean. Q. J. R. Meteorol. Soc. 77: 598-626

Selling, O. H. (1948). Studies in Hawaiian pollen statistics. Part III. On the late Quaternary history of the Hawaiian vegetation. Bernice P. Bishop Mus. Spec. Publ. 39

Manuscript first received: February 16, 1991

Revised version accepted: June 21, 1991 